\title{
Research on the Package Feature Selection of Talent Attracting Factors in International Trade in Guangdong-Hong Kong-Macao Greater Bay Area
}

\author{
Fei Lei ${ }^{1, \mathrm{a}}$, Liangmei $\mathrm{Luo}^{2, *}$, Hang Yang ${ }^{1, \mathrm{~b}}$, Qinhui $\mathrm{Li}^{3, \mathrm{c}}$, Feng Chen ${ }^{4, \mathrm{~d}}$ \\ ${ }^{1}$ School of Finance and Economics, Guangdong University of Science and Technology, Dongguan, China \\ ${ }^{2}$ School of Public Administration, Xinhua college of sun yat-sen University, Tianhe, Guangzhou, China \\ ${ }^{3}$ School of Management, Xinhua college of sun yat-sen University, Tianhe, Guangzhou, China \\ ${ }^{4}$ Tourism Business College, Guangzhou Panyu Vocational and Technical College, Guangzhou, China
}

\begin{abstract}
This paper designs a survey questionnaire based on the Guangdong-Hong Kong-Macao Greater Bay Area's demand for talents in international trade, adds job types, filters through package features, and performs feature filtering with the error filter criteria set in this paper, and conducts logistic regression analysis on talent types, so as to realize the classification and dynamic analysis of talents. The dynamic needs of various types of talents in international trade in the Guangdong-Hong Kong-Macao Greater Bay Area are drawn, and specific measures such as increasing salaries and benefits, reducing living costs, providing housing subsidies, solving children's employment problems, and ensuring quality of life are proposed for the development of international trade talents. Reducing the cost of talent migration can promote them to make more contributions to the Guangdong-Hong Kong-Macao Greater Bay Area. This will help the Guangdong-Hong Kong-Macao Greater Bay Area government to attract outstanding international trade talents and formulate detailed and feasible strategies, which has certain reference significance.
\end{abstract}

\section{Questions raised}

The proportion of China's labor force (the population between the ages of 15 and 59) has reached an inflection point in 2010, which means that China's demographic dividend has begun to fade; as shown in Figure 1. Therefore, governments throughout China continue to formulate new policies to increase their efforts to attract outstanding talents. In order to maintain its competitiveness and innovation, the Guangdong-Hong Kong-Macao Greater Bay Area must attract talents. In order to attract outstanding talents and promote the development of the industry, local government departments focus on attracting talents. The migration cost, salary or benefits, work location, different industries, career development, cost of living, etc. are the primary considerations; again, the work environment factors: convenient transportation, children's education, medical and health, local environment, social security and so on. At present, there are few quantitative researches and more qualitative discussions in this area. In quantitative research, there are many single factors and few comprehensive factors; there are few dynamic considerations, many static considerations, and fewer incomparable conditions can be considered. The main reason is the lack of appropriate mathematical models, and the conclusions lack persuasiveness and verifiability. Collect data to establish a mathematical model to quantify the level of talent attractiveness in the Guangdong-Hong Kong-Macao Greater Bay Area, improve the talent environment, and create a sample of decentralized governance and service reforms in the Guangdong-Hong Kong-Macao Greater Bay Area to attract talents in the Guangdong-Hong Kong-Macao Greater Bay Area Make a quantifiable evaluation of the level.

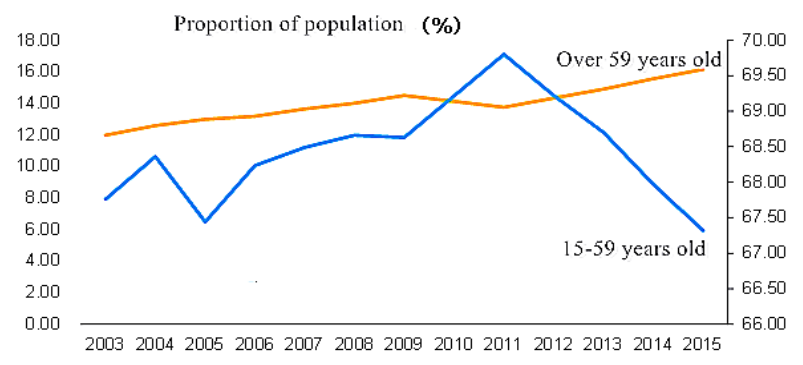

Fig. 1. The proportion of China's labor force has reached a turning point in 2010 (Source: National Bureau of Statistics of China)

\section{Literature review}

Human resources refer to those people in a country or region who have more scientific knowledge and strong labor skills, and play a key or important role in the value creation process. Human resources are part of human

\footnotetext{
${ }^{*}$ Corresponding author: pallm@xhsysu.edu.cn
} 
resources, that is, high-quality human resources. Wrapped feature selection directly uses the performance of the final learner as the criterion for subset evaluation. From the performance point of view, the wrapped option is better than the filtered option. LVW (Las Vegas Wrapper) is a typical wrapper feature selection method.

The development of the Bay Area requires talents first. Having a comprehensive and abundant talent attraction plays an important role in regional development. By combing through the literature on talent attractiveness in the past ten years, it is found that the current research on talent attractiveness focuses on the theoretical research of talent attractiveness evaluation index model and the research of regional or industry talent attractiveness factors. In terms of theoretical research on talent attractiveness evaluation index models, many scholars (Wang Chongxi and $\mathrm{Hu}$ Bei, 2007; Zhou Junxu, 2010; Hu Bentian, 2020) from the macro level of regional economic development, the meso level of industrial clusters, and organizational attractiveness Establish multiple variables at the micro level such as individual perception, and design multiple indicators for research. Hu Lian, Zhao Yexin (2020) analyzed the influencing factors of urban talent attractiveness through factor analysis and made comprehensive scores and rankings. The results showed that the income of regional residents, regional economic development, and regional scientific and technological development and investment are the most important factors for cities to attract talents. Important factors; in terms of research methods and models; [1] Hou Wenfeng (2020) constructed a quantitative model of Shenzhen talent attraction based on the analytic hierarchy process, and selected five firstlevel indicators of salary, rent, diet, conversation, and medical care; [2] Kong Lina (2019) calculated the weight of each indicator based on the entropy weight TOPSIS model to objectively assign weights to evaluate the attractiveness of talents. [3] In terms of research on the attractive factors of regional or industry talents, some scholars, from the perspective of development economics, take the growth pole theory proposed by the famous French economist François Perroux as the starting point, and believe that regional attractiveness comes from The attractiveness of various resources, especially human capital, also believes that the allocation of geographic space and industrial development attracts talents: For example, Huang Xiangmin (2013), from the perspective of industrial agglomeration, believes that regional industrial agglomeration and talent agglomeration are complementary;[4]Wang Ning (2014) believes that the attractiveness of a place for talents comes from two aspects, one is from the level that the place occupies in the national local hierarchical system, and the other is from the de-embedding of talents, regional advanced industries and characteristic resource elements. It will be easy to attract talents.[5] Supplementing a document about the package type, see if it works: With the development of machine learning technology, Cai Jingbo (2020) studied the prediction of certain economic and policy phenomena based on machine learning models [i];[6] Therefore, This article can be used for reference in the evaluation of talent attractiveness factors.

It can be seen that with the development of the economy, the research on talent attraction has become more and more abundant, and it has experienced a comprehensive index evaluation system from qualitative analysis to quantitative evaluation, from a few indicators to multiple indicators. However, there is still a blank in the research on talent attraction in the international trade field with distinctive characteristics in the Greater Bay Area. The consideration of the attractiveness of talents in specific fields is still to be explored.

\section{3 problem analysis}

Based on question, in order to obtain the GuangdongHong Kong-Macao Greater Bay Area international trade talent attraction model. First, according to the requirements of the topic and previous studies on the talent attraction factors of the Guangdong-Hong KongMacao Greater Bay Area, we will find suitable factors for attracting talents in the international trade of the Guangdong-Hong Kong-Macao Greater Bay Area, and finally establish a four-dimensional framework of talent attraction factors for the Guangdong-Hong Kong-Macao Greater Bay Area. There are four dimensions of the career environment: salary and benefits, cost of living, career development, and business conditions; four dimensions of family security: work location, housing conditions, spouse employment, and children's education; and there are four questions about gender, monthly income, and nature of work. Through various channels such as WeChat and QQ, the questionnaires were distributed and finally 602 questionnaires were obtained. Data analysis was performed on the acquired data, and the packaged feature selection (logistic regression bit-based learner) was used to select different features and set up After determining the error threshold, it is finally determined that all features are within the error threshold. Then use Logistics logistic regression to perform regression analysis on the data to get the formula.

\section{Model assumptions}

Assuming that the data distribution of the difference adjustment questionnaire is different from the distribution of the demand for international trade talents in the Guangdong-Hong Kong-Macao Greater Bay Area, it has no significant impact on the final result.

\subsection{Assuming that the data in the questionnaire is adjusted, there are no repeated survey questions.}

\subsection{Assuming that in the questionnaire, the respondent's answer is true and credible.}




\section{Symbol Description}

Symbol description is shown in Table 1.

Table 1. Symbol description

\begin{tabular}{|c|c|c|c|}
\hline $\begin{array}{l}\text { Sym } \\
\text { bol }\end{array}$ & $\begin{array}{c}\text { Symbol } \\
\text { Explanation }\end{array}$ & $\begin{array}{l}\text { Sym } \\
\text { bol }\end{array}$ & $\begin{array}{c}\text { Symbol } \\
\text { Explanation }\end{array}$ \\
\hline Y1 & Is it attractive & Env & Ecosystem \\
\hline Y2 & $\begin{array}{l}\text { Is it attractive to } \\
\text { international } \\
\text { trade engineering } \\
\text { technology } \\
\text { research and } \\
\text { development } \\
\text { talents }\end{array}$ & Cost & living cost \\
\hline Y3 & $\begin{array}{l}\text { Is it right } \\
\text { International } \\
\text { trade } \\
\text { management and } \\
\text { sales talents are } \\
\text { attractive }\end{array}$ & $\begin{array}{l}\text { Com } \\
\text { env }\end{array}$ & $\begin{array}{l}\text { Enterprise } \\
\text { conditions }\end{array}$ \\
\hline Y4 & $\begin{array}{l}\text { Is it right } \\
\text { International } \\
\text { trade service } \\
\text { talents are } \\
\text { attractive }\end{array}$ & Edu & $\begin{array}{l}\text { Children's } \\
\text { education }\end{array}$ \\
\hline Ente & $\begin{array}{l}\text { Salary and } \\
\text { benefits }\end{array}$ & Pla & work place \\
\hline
\end{tabular}

\section{Model establishment and solution}

\subsection{The establishment and solution of problem one model}

Using WeChat and QQ social software to distribute questionnaires and collect data and information, a total of 605 questionnaires were obtained in three days, of which males accounted for $57.8 \%$ and females accounted for $42.2 \%$. Preliminary processing of the data obtained and non-dimensionalization of the attractiveness elements in the questionnaire will be very capable, relatively capable, general, and unable to be converted into 4, 3, 2, 1, and then normalized, and at the same time Convert the answer to the question of attractiveness into 1 and 0 . For the original data, some data have obvious abnormalities, but because the data volume and dimension are small, the subspace abnormal point detection algorithm and the regional abnormal point detection algorithm have large errors, so data analysis is adopted. Set manual rules to screen out abnormal points, and then compare before and after through a variety of classification algorithms, the training error and test error are reduced.

\subsection{The establishment and solution of problem one model}

\subsubsection{Feature selection}

Wrapped feature selection is to select a base learner, and then perform cyclic feature division on it, and then verify the $n$-fold difference of the data set after different feature divisions, and then obtain the best on these features according to the evaluation function Feature division method, and evaluation scores of different feature division methods. As for the error problem of the base learner in the wrapped feature selection. Suppose the error $\mathrm{W}$ is the difference between the average accuracy of cross-validation for each type of feature selection and the average accuracy of the best type of feature selection when the wrapped feature selection is missing. The difference between the maximum accuracy rate and the minimum accuracy rate is judged to be normal. After feature selection, the results obtained prove that the previously established features are all within a reasonable error range.

\subsubsection{Logistic regression analysis of the data}

Logistic regression (Logistic regression), that is, the logistic model is one of the discrete choice models, a generalized linear regression analysis model, belonging to the category of multivariate analysis, including sociology, biostatistics, clinical, quantitative psychology, and econometrics, Marketing and other common methods of statistical empirical analysis. Logistics regression analysis is a commonly used variable generalized linear regression analysis model, and its independent variables can be continuous or categorical. Through Logistics regression analysis, the weights of the independent variables can be obtained, so as to roughly understand which factors are the reasons for the results. The model is established as follows:

$Y 1=\operatorname{Ente}(0.572 B a s 1)+(0.223 E n v 1)+0.20 P l a 1+0.735 E d$ $u 1+(-0.887$ Comenv 1$)+(-0.215$ Cost 1$)$

\subsubsection{Model analysis}

For talents as a whole, the Guangdong-Hong KongMacao Greater Bay Area's salary and benefits, work location, cost of living, and children's education all have a positive impact. However, the corporate conditions and housing conditions in the Guangdong-Hong KongMacao Greater Bay Area have a negative impact on them. The housing prices in the Guangdong-Hong KongMacao Greater Bay Area are indeed increasingly disproportionate to their income levels. 
6.2.4 The talent attraction policy of the GuangdongHong Kong-Macao Greater Bay Area plays a positive role in the attractiveness of talents

The Guangdong-Hong Kong-Macao Greater Bay Area's talent attraction policies play a positive role, mainly in the cost of living and salary and benefits. Therefore, we can determine that the Guangdong-Hong Kong-Macao Greater Bay Area's talent-attracting policy has an impact on the salary, benefits and cost of living in the Guangdong-Hong Kong-Macao Greater Bay Area. Has a positive and beneficial impact.

\subsection{Establishment and solution of the question model}

\subsubsection{An analysis of the types of talents needed in international trade in the Guangdong-Hong Kong- Macao Greater Bay Area}

The demand for international trade talents in the Guangdong-Hong Kong-Macao Greater Bay Area is divided into roughly three types. The first is the technology research and development of international trade products, including product design, quality control and production engineering for international trade companies, such as design engineers in the mechanical and electronic industries, Quality engineers, production engineers, etc.; second, international trade management and sales, senior management and sales personnel; third, international trade service staff, such as international trade personnel engaged in import and export warehousing, transportation, etc.

\subsubsection{The talent attractiveness of the Guangdong- Hong Kong-Macao Greater Bay Area is modeled by type}

Logistic regression analysis based on the types of talents in the Guangdong-Hong Kong-Macao Greater Bay Area.

International trade management and sales talent model:

$Y 2=E n t e(0.451$ Bas 2$)+0.434 E n v 2+1.20 P l a 2+0.842 E d u 2$ $+(-0.920$ Comenv 2$)+(-0.315$ Cost 2$)$

International trade engineering and technical personnel model:

\section{$Y 3=$ Ente $(0.600$ Bas 3$)+0.254$ Env $3+1.10$ Pla $3++0.913 E d$ u3 (-0.727Comenv3) $+(-0.523$ Cost 3$)$

International Trade Service Type Model:

\section{$Y 4=E n t e(0.832 B a s 4)+0.125 E n v 4+1.00 P l a 4+0.528 E d u 4$ $+(-0.319$ Comenv 4$)+(-0.616$ Cost 4$)$

After statistical data analysis, the regression analysis data of international trade talents required by the Guangdong-Hong Kong-Macao Greater Bay Area is shown in Table 2.

Table 2. Talent regression analysis data

\begin{tabular}{|c|c|c|c|c|}
\hline & Talent overall & $\begin{array}{c}\text { Management } \\
\text { and sales }\end{array}$ & $\begin{array}{c}\text { Engineering, } \\
\text { technical }\end{array}$ & Service \\
\hline living cost & 0.371 & 0.549 & 0.351 & 0.287 \\
\hline Enterprise conditions & -0.30 & -0.35 & -0.52 & -0.61 \\
\hline Career Development & 0.887 & 0.918 & 0.730 & 0.319 \\
\hline Salary level & 0.353 & 0.424 & 0.578 & 0.550 \\
\hline Housing conditions & $\begin{array}{c}0.570 \\
-0.73\end{array}$ & $\begin{array}{c}0.450 \\
-0.89\end{array}$ & $\begin{array}{c}0.600 \\
-0.74\end{array}$ & $\begin{array}{c}-0.53 \\
3\end{array}$ \\
\hline work place & 0.204 & 1.182 & 1.100 & 1.000 \\
\hline Spouse employment & -0.63 & -0.10 & -0.38 & -0.59 \\
\hline Children's education & 0.735 & 0.434 & 0.252 & 0.528 \\
\hline Traffic status & -0.28 & -0.59 & -0.53 & -0.44 \\
\hline Work benefits & 0.576 & 0.895 & $\begin{array}{c}0.281 \\
6\end{array}$ \\
\hline
\end{tabular}


After statistical data analysis, the regression analysis data of international trade talents required by the Guangdong-Hong Kong-Macao Greater Bay Area is shown in Table 2.

\subsection{Make policy recommendations through models}

Talents in the Guangdong-Hong Kong-Macao Greater Bay Area are more concerned about the five factors of salary and benefits, work location, career development, children's education, and cost of living. Therefore, talents should reduce their migration costs, increase their salaries and benefits, and provide rental subsidies as appropriate. We should further deepen the reform of decentralization, management and service, reduce the cost of living, and improve the ability of relevant parties to attract talents. As for children's education, the five dimensions of transportation status and the ecological environment, it is necessary to better solve the problems of living costs, salary and benefits, and children's education, and further improve the traffic conditions in Guangdong, Hong Kong and Macao, and provide guarantee and support for the quality of life of talents.

\section{7 conclusion}

The Guangdong-Hong Kong-Macao Greater Bay Area is one of the regions with the highest degree of openness and strongest economic vitality in China, and it has an important strategic position in the overall development of China. Although the Guangdong-Hong Kong-Macao Greater Bay Area has its advantages in attracting talents: a solid economic foundation, a complete industrial chain; a large number of scientific research institutions and innovation institutions, and a strong ability to attract talents; transportation, port clusters, medical care, culture and education that serve talents are guaranteed In place; there are international open traditions and realistic conditions. However, in the context of the ongoing SinoUS trade war, in the post-epidemic era, China's external circular economy is facing greater challenges. The demand for international trade talents with cross-cultural business communication in cities in the Greater Bay Area is stronger. This paper adopts The research method of the questionnaire analyzes the needs of selfdevelopment of international trade talents in the Guangdong-Hong Kong-Macao Greater Bay Area: such as the need to increase wages and benefits, reduce living costs, provide housing subsidies, solve children's school enrollment and ensure industrial development, etc., all parts of the Bay Area The government should provide more effective policies for the development needs of international trade talents to attract and retain such talents. Based on this, the governments of the Guangdong-Hong Kong-Macao Greater Bay Area should boldly explore and reform the existing systems and mechanisms, effectively attract the introduction of international trade talents and give full play to their role, which can promote the better and more robust development of the circular economy outside the cities where talents are located.

\section{Model evaluation}

\subsection{Model advantages}

Established the judgment standard of the wrapped feature analysis-based learner, avoiding the problem of inaccurate subjective judgments in the past.

\subsection{Model shortcomings}

The amount of data is small, and the later classification model has the problem that the chi-square test cannot be performed.

\section{Model improvement}

A larger-scale data survey was conducted based on random sampling surveys, and a quantitative evaluation system for the reform of professional decentralization, management and service was established.

\section{Acknowledgements}

This article is one of the phased achievements of the "2020 Dongguan City Philosophy and Social Science Planning Project "Research on the Flexible Talent Induction Mechanism in the Construction of Dongguan Talent Highland"" and "The Research Project of the Postdoctoral Innovation Base for Harmonious Labor Relations of the Human Resources and Social Affairs Bureau of Huadu District, Guangzhou" One.

\section{References}

1. L.Z.Hu, X.Ye, Analysis and Comprehensive Evaluation of the Influencing Factors of Urban Talent Attractiveness: Taking the Second-tier Cities in Mainland China as an Example, .Journal of Jiangsu Ocean University (Humanities and Social Sciences Edition),18(04):125-132(2020)

2. W.F.Hou, F.Y., Liu, L.S.Cao ,.Shenzhen talent attractiveness quantitative model based on analytic hierarchy process, Science Consulting (Technology·Management), (04):133(2020)

3. L.L.Sun, B. Xian, J.M.Zhu, The evaluation of talent attraction based on entropy weight TOPSIS model, Natural Science Journal of Harbin Normal University, 35(02):30-34(2019).

4. R.G.Li, The Theory and Policy of Growth Pole in Regional Economic Development, .Economic Research,(09):63-70(1988)

5. L.Wang, Local stratification, talent mobility and urban talent attraction-the second study of "geographic mobility and social mobility", Journal 
of Tongji University (Social Science Edition), 25(06): 47-55 +109(2014)

6. J.B. Cai, Z.J. Cai, Based on machine learning model to predict high-send stocks in the A-share market, Mathematical Modeling and Its Applications, 9(04): 74-84(2020) 